\title{
Retrospective Study of Transjugular Intrahepatic Portosystemic Shunt Placement for Cirrhotic Portal Hypertension
}

\author{
Sara Santos ${ }^{a}$ Eduardo Dantas $^{b}$ Filipe Veloso Gomes ${ }^{c, d}$ José Hugo Luz ${ }^{c, d}$ \\ Nuno Vasco Costa ${ }^{c, d}$ Tiago Bilhim ${ }^{c, d}$ Filipe Calinas $^{a}$ Américo Martins $^{e}$ \\ Élia Coimbrad
}

aGastroenterology and Hepatology Department, Centro Hospitalar Universitário de Lisboa Central (CHULC), Lisbon, Portugal; ${ }^{b}$ Gastroenterology and Hepatology Department, Centro Hospitalar de Setúbal, Setúbal, Portugal; 'NOVA Medical School, Lisbon, Portugal; ' Interventional Radiology Unit, Curry Cabral Hospital, Centro Hospitalar

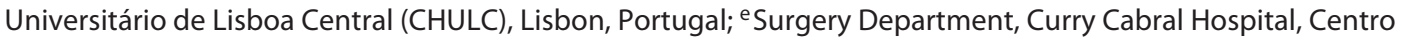
Hospitalar Universitário de Lisboa Central (CHULC), Lisbon, Portugal

\section{Keywords}

Transjugular intrahepatic portosystemic shunt .

Portal hypertension

\section{Abstract}

Background and Aims: Transjugular intrahepatic portosystemic shunt (TIPS) is used for decompressing clinically significant portal hypertension. The aims of this study were to evaluate clinical outcomes and adverse events associated with this procedure. Methods: Retrospective single-center study including 78 patients submitted to TIPS placement between January 2015 and November 2018. Follow-up data were missing in 27 patients, and finally 51 patients were included in the study sample. Data collected from individual registries included demographics, comorbidities, laboratory results, complications, and clinical results according to the indication. Results: Average pre-TIPS portosystemic pressure gradient decreased from $18.1 \pm 5$ to $6 \pm 3 \mathrm{~mm} \mathrm{Hg}$ after TIPS placement. Indications for TIPS were refractory ascites $(63 \%, n=49)$, recurrent or uncontrolled variceal bleeding $(36 \%, n=28)$, and Budd-Chiari syndrome $(1.3 \%, n=1)$. TIPSrelated adverse events occurred in 29/51 (56.8\%) patients, with hepatic encephalopathy (HE) in 21 (41\%) patients, sep- sis in 3 , liver failure in 2 , hemolytic anemia in 1 , acute pulmonary edema in 1, and capsular perforation in 1 patient. Mean follow-up was $15.7 \pm 15$ months. First-month mortality was $11.7 \%(n=6)$ (sepsis, $n=3$; acute liver failure, $n=2$; and recurrence of variceal bleeding, $n=1$ ) and was significantly higher for patients with Child-Pugh $>9$ points $(p=0.01)$, model of end-stage liver disease (MELD) scores $>19$ ( $p=$ 0.02 ), and for patients with a history of HE before the procedure $(p=0.001)$. Older age $(p=0.006)$ and higher levels of creatinine $(p=0.008)$ were significantly higher in patients developing HE after TIPS. Ascites persisted in 21.2\% (7/33 patients) and was more frequent in patients with lower baseline albumin levels $(p=0.003)$. Recurrent variceal bleeding occurred in $22 \%$ ( $n=4 / 18$ patients) and was more frequent in patients with lower baseline hemoglobin levels $(p=0.03)$. Conclusion: TIPS is effective in up to $80 \%$ of patients presenting with variceal bleeding or refractory ascites. Careful patient selection based on age and HE history may reduce adverse events after TIPS.

C 2020 Sociedade Portuguesa de Gastrenterologia Published by S. Karger AG, Basel

Sara Santos and Eduardo Dantas share first authorship. karger@karger.com www.karger.com/pjg

(c) 2020 Sociedade Portuguesa de Gastrenterologia Published by S. Karger AG, Basel

\section{Karger $\stackrel{2}{=}$}

GOPEN ACCESS

This article is licensed under the Creative Commons AttributionNonCommercial-NoDerivatives 4.0 International License (CC BYNC-ND) (http://www.karger.com/Services/OpenAccessLicense). Usage and distribution for commercial purposes as well as any distribution of modified material requires written permission.

Sara Santos

Azinhaga Barros 8, R/C D

PT-1600-016 Lisbon (Portugal)

saramendezleiria@ hotmail.com 


\section{Estudo retrospetivo de colocação de shunt portossistémico transjugular intrahepático na hipertensão portal cirrótica}

\section{Palavras Chave}

Shunt portossistémico transjugular intra-hepático · Hipertensão portal

\section{Resume}

Introdução e Objectivos: O shunt portossistémico transjugular intra-hepático (TIPS) é usado para descompressão de hipertensão portal hepática clinicamente significativa. Os objetivos deste estudo foram avaliar os resultados clínicos e efeitos adversos associados a este procedimento. Métodos: Estudo retrospectivo de centro único, incluindo 78 pacientes submetidos ao procedimento entre Janeiro de 2015 e Novembro de 2018. Os dados de seguimento estavam ausentes em 27 doentes, tendo sido incluídos 51 doentes na análise. Os dados colhidos de registos individuais incluíram dados demográficos, comorbilidades, resultados laboratoriais, complicações e resultados clínicos, de acordo com a indicação. Resultados: $O$ gradiente médio de pressão portossistémica pré-TIPS foi de $18.1 \pm 5 \mathrm{~mm} \mathrm{Hg}$, que diminuiu para $6 \pm 3 \mathrm{~mm} \mathrm{Hg}$. Indicações para TIPS foram ascite refratária $(65 \%, n=33)$ e hemorragia varicosa recorrente/refratária (35\%, $n=18$ ). As complicações relacionadas ao TIPS ocorreram em 29 doentes (56.8\%): encefalopatia hepática $(E H)$ em 21 doentes, sépsis $(n=3)$, insuficiência hepática $(n=2)$, anemia hemolítica $(n=1)$, edema pulmonar agudo $(n=1)$ e perfuração capsular $(n=1)$. O seguimento médio foi de $15.7 \pm 15$ meses. A mortalidade no primeiro mês foi de $11.7 \%(n=6)$ (sépsis, $n=3$; insuficiência hepática aguda, $n=2$; recorrência de hemorragia varicosa, $n=1$ ), e foi significativamente mais frequente em doentes com Child-Pugh $>9$ pontos ( $p=0.01$ ), pontuação de MELD >19 pontos $(p=0.02)$ e história de EH prévia ao procedimento $(p=0.001)$. Doentes que desenvolveram EH tinha mais frequentemente idade avançada $(p=0.006)$ e níveis mais elevados de creatinina ( $p=0.008$ ). A ascite persistiu em $21.2 \%$ (7/33 doentes), mais habitualmente em doentes com níveis mais baixos de albumina basal $(p=0.003)$. Hemorragia varicosa recorrente ocorreu em $22 \%$ ( $n=4 / 18$ doentes), em associação com níveis mais baixos de hemoglobina ( $p=$ 0.03). Conclusão: O TIPS é eficaz em $80 \%$ dos doentes que apresentam hemorragia varicosa ou ascite refratária. Eventos adversos podem ser reduzidos através da seleção de doentes, com base na idade e história de EH.

C 2020 Sociedade Portuguesa de Gastrenterologia Publicado por S. Karger AG, Basel

\section{Introduction}

The potential utility of transjugular intrahepatic portosystemic shunt (TIPS) placement was first proposed in 1969 by J. Rosch. The first TIPS procedure, performed in 1988 by M. Rössle, was done with the purpose of relieving portal hypertension [1]. Several studies and international guidelines have addressed the potential usefulness of this procedure in the management of cirrhosis complications refractory to conventional therapy. One of the most notable advances in this technique has been the use of expandable PTFE (polytetrafluorethylene)-covered stents, which significantly lowered occlusion rates compared to the previously used bare-metal stents, thereby improving long-term stent patency. These stents are now considered standard of care [1-4].

Refractory ascites and recurrent or treatment-refractory acute variceal bleeding are the two main established indications for TIPS placement. The value of an early TIPS placement in patients with acute variceal bleeding with high risk of early rebleeding has also been proposed in patients with Child-Pugh score $\leq 13[1,5]$.

The major complication of this procedure continues to be hepatic encephalopathy $(\mathrm{HE})$, requiring appropriate selection of patients and preferential use of shunts with smaller diameters. Selection criteria and liver function assessment can be performed using several scoring systems. The model of end-stage liver disease (MELD) score was developed to predict early mortality after TIPS and is now used as a severity index of liver function. In addition, high Child-Pugh scores are regarded as a relative contraindication to TIPS placement $[1,4]$.

Liver transplantation remains the definitive treatment for complications related to cirrhosis, but the lack of adequate organ supply can lead to higher mortality and dropout while on the liver transplant waiting list. In this context, TIPS placement assumes a primary role as a bridge to liver transplantation.

We sought to study the clinical outcomes and adverse events related to TIPS placement in a cohort of patients with decompensated cirrhosis.

\section{Subjects and Methods}

\section{Design, Setting, and Participants}

This is a single-center retrospective study that included all consecutive adult patients ( $\geq 18$ years) diagnosed with liver cirrhosis who underwent TIPS placement for treatment of portal hypertension related complications at the Interventional Radiology Unit of the Curry Cabral Hospital (Lisbon, Portugal) between January 
2015 and November 2018. We started patient enrolment at this time point due to the quality of data recorded from then on. We included patients with a diagnosis of liver cirrhosis and complications related to portal hypertension submitted to the procedure due to acute refractory or recurrent variceal bleeding that could not be controlled with conventional therapy or refractory ascites. Patients undergoing liver transplantation were censored during follow-up at the date of liver transplant. Given the observational character of the study, the local ethics committee waived the need for individual informed consent. The principles of the Declaration of Helsinki were respected throughout the study [6].

Procedure, Data Collection, and Endpoints

All procedures were performed in the Interventional Radiology Unit by 3 interventional radiologists with 20, 9, and 4 years of experience; TIPS was performed using a $10-\mathrm{mm}$ expandable PTFEcovered stent (Viatorr ${ }^{\circledR}$ TIPS endoprosthesis; Gore, Flagstaff, AZ, USA). All TIPS procedures were performed under general anesthesia with a portosystemic pressure gradient (PPG) measured before and after successful completion of the procedure. TIPS patency was evaluated by Doppler ultrasound 2-8 weeks after the procedure. Data on the study population characteristics were retrieved from individual patient clinical files. The measured outcomes were: technical/hemodynamic success, procedure-related adverse events, first-month mortality following the procedure and orthotopic liver transplant (OLT)-free survival. Technical success was considered as effective creation of a shunt between the hepatic and portal venous system, and hemodynamic success as a decrease in PPG to $\leq 12 \mathrm{~mm} \mathrm{Hg}$ or a reduction of at least $20 \%$.

Clinical success concerning recurrent bleeding and ascites response according to TIPS indication was evaluated. Partial ascites response was considered when no further paracentesis was necessary despite the presence of clinically detectable ascites. Total response was defined as absence of ascites with or without the use of diuretics.

\section{Data Analysis}

Baseline characteristics are described as numbers (\%) for categorical variables and medians with interquartile ranges (IQR) or means with standard deviations (SD) for continuous variables. Baseline characteristics were compared between patients with different outcomes by $\chi^{2}$ test for qualitative variables and Student's $t$ test or Mann-Whitney test for quantitative variables. Statistical significance was set at $p<0.05$. Statistical analysis was performed using SPSS v25 (2017).

\section{Results}

\section{Study Population and Technical Outcomes}

In this study period, 78 procedures were performed with $97.4 \%(n=76)$ technical success. Hemodynamic success, defined by a final PPG of $12 \mathrm{~mm} \mathrm{Hg}$ or less, or a reduction of at least $20 \%$, was achieved in all patients with technical success $(n=76)$. In the 1 patient with final PPG $>12 \mathrm{~mm} \mathrm{Hg}$, reduction was superior to $20 \%$. Indications for TIPS were refractory ascites $(63 \%, n=49)$, recurrent
Table 1. Baseline main demographic and clinical characteristics of the study population $(n=51)$

\begin{tabular}{lc}
\hline Sex, male & $38(75 \%)$ \\
Age, years & $56 \pm 12$ \\
Indication for TIPS, ascites/variceal & \\
$\quad$ bleeding & $33 / 18(65 / 35 \%)$ \\
Child-Pugh & \\
$\quad$ A & $3(5.8 \%)$ \\
B & $41(80.4 \%)$ \\
C & $7(13.7 \%)$ \\
MELD & $13.7 \pm 5.2$ \\
MELD-Na & $15.8 \pm 6$ \\
Etiology of liver disease & \\
$\quad$ Alcohol & $29(57 \%)$ \\
$\quad$ Both alcohol + HCV/HBV & $9(18 \%)$ \\
Cryptogenic & $5(10 \%)$ \\
$\quad$ HCV & $3(6 \%)$ \\
PBC & $2(4 \%)$ \\
$\quad$ NASH & $2(4 \%)$ \\
$\quad$ Wilson disease & $1(2 \%)$ \\
Previous hepatic encephalopathy & $7(14 \%)$ \\
Comorbidities (hypertension, coronary & \\
$\quad$ artery disease, and type 2 diabetes) & $16(31 \%)$ \\
Serum Na, mEq/L & $139 \pm 5.3$ \\
INR & $1.3 \pm 0.19$ \\
Creatinine, mg/dL & $1.4 \pm 0.82$ \\
Total bilirubin, mg/dL & $1.95 \pm 2.9$ \\
Albumin, mg/dL & $32.6 \pm 5.8$ \\
Platelet count, $\times 10^{9} / \mathrm{L}$ & $128 \pm 71.3$ \\
Hemoglobin, g/dL & $10.2 \pm 2.6$ \\
\hline
\end{tabular}

Continuous variables are presented as means $\pm \mathrm{SD}$, categorical variables as numbers (\%). $\mathrm{HBV} / \mathrm{HCV}$, hepatitis $\mathrm{B} / \mathrm{C}$ virus; INR, international normalized ratio; MELD, model of end-stage liver disease; NASH, nonalcoholic steatohepatitis; $\mathrm{PBC}$, primary biliary cirrhosis; TIPS, transjugular intrahepatic portosystemic shunt.

or uncontrolled variceal bleeding $(36 \%, n=28)$, and Budd-Chiari syndrome $(1.3 \%, n=1)$. Pre-TIPS mean PPG was $18.1 \pm 5 \mathrm{~mm} \mathrm{Hg}$, which decreased to $6 \pm 3 \mathrm{~mm}$ $\mathrm{Hg}$ after TIPS. The mean decrease was $12 \pm 5 \mathrm{~mm} \mathrm{Hg}$.

Two patients with technical failure of TIPS placement were excluded. In addition, 16 patients whose indication was refractory ascites and 9 patients whose indication was variceal bleeding were excluded due to loss of follow-up. Therefore, the final study sample included 51 patients with indications for TIPS being refractory ascites $(65 \%$, $n=33)$ and uncontrolled or early severe recurrent variceal bleeding $(35 \%, n=18)$.

The mean follow-up time until liver transplant, death, or date of data collection was $15.7 \pm 15$ months. Fifteen patients (19.7) underwent liver transplantation for end-stage liver disease $8 \pm 6$ months after TIPS placement. Most pa- 
Table 2. Comparison of baseline data of patients with versus without hepatic encephalopathy (HE) development or worsening

\begin{tabular}{lccl}
\hline Variables & $\begin{array}{l}\text { HE } \\
(n=21)\end{array}$ & $\begin{array}{l}\text { No HE } \\
(n=30)\end{array}$ & $\begin{array}{l}p \\
\text { value }\end{array}$ \\
\hline Age, years & $59(10)$ & $51(13)$ & 0.006 \\
Child-Pugh & $8(2)$ & $7.5(2)$ & 0.3 \\
MELD & $12(6)$ & $13(6.5)$ & 0.5 \\
Baseline creatinine, mg/dL & $1.58(0.9)$ & $0.96(0.8)$ & 0.008 \\
Baseline albumin, $\mathrm{mg} / \mathrm{dL}$ & $33.5(10.5)$ & $31(9)$ & 0.2 \\
Baseline serum $\mathrm{Na}^{+}, \mathrm{mEq} / \mathrm{L}$ & $134(8)$ & $137(12)$ & 0.08 \\
Baseline platelet count, $\times 10^{9} / \mathrm{L}$ & $127(82)$ & $97(127)$ & 0.49 \\
PPG reduction, mm Hg & $12(5)$ & $12(9)$ & 0.55 \\
Final PPG, mm Hg & $6(2.5)$ & $6(5.5)$ & 0.4 \\
\hline
\end{tabular}

Continuous variables are presented as medians (IQR). PPG, portosystemic pressure gradient. See legend to Table 1 for further information.

tients were male $(75 \%, n=38)$, with a mean age of $56 \pm 12$ years (22-76). Cirrhosis was most frequently due to alcohol $(57 \%, n=29)$, and both alcohol and hepatitis C/B (18\%, $n=9)$. Other etiologies along with baseline data are summarized in Table 1. The Child-Pugh score was class A in 3 patients, $B$ in 41 patients, and $C$ in 7 patients. Mean MELD score was $13.7 \pm 5.2(7-33)$ and MELD-Na $15.8 \pm 6$ (7-36). Forty-seven patients (92\%) had previous episodes of cirrhosis decompensation and a prior episode of HE in $14 \%$ $(n=7)$. Status of alcohol consumption was not registered in all patients, for whom these data were not included.

\section{Adverse Events}

Adverse events related to TIPS occurred in 29 patients (56.8\%), most of them due to development or worsening of HE (21 patients; $41 \%$ ); in the remainder, adverse events were attributable to sepsis $(n=3)$, hepatic failure $(n=2)$, hemolytic anemia $(n=1)$, acute pulmonary edema $(n=$ $1)$, and capsular perforation $(n=1)$. HE occurred in 21 patients (41\%) during follow-up, with 19 patients (90\%) developing grade I-II HE according to the West-Haven classification and 2 patients with grade III HE. The median time until HE development was 1 (2.8) month after the procedure. Older age and higher levels of creatinine were significantly higher in patients developing $\mathrm{HE}$ (Table 2). Concerning shunt dysfunction, stent thrombosis occurred in 2 patients: recanalization with anticoagulation was possible in 1 patients, and, in another patient, stenosis was successfully treated with angioplasty.

In this population, 6 patients $(11.7 \%)$ died within 1 month after TIPS procedure. Early mortality was due to
Table 3. A comparison of baseline data between patients who died and those who survived after TIPS

\begin{tabular}{lccl}
\hline Variables & $\begin{array}{l}\text { Death } \\
(n=6)\end{array}$ & $\begin{array}{c}\text { Survival } \\
(n=45)\end{array}$ & $\begin{array}{l}p \\
\text { value }\end{array}$ \\
\hline $\begin{array}{l}\text { Age, years } \\
\text { Indication, } n\end{array} \quad$ Ascites & $57(15.5)$ & $59(17.5)$ & 0.1 \\
$\quad$ Variceal bleeding & $3(9 \%)$ & $30(91 \%)$ & 0.3 \\
Child-Pugh & $3(18 \%)$ & $14(82 \%)$ & \\
MELD & $10.5(3.3)$ & $8(2)$ & 0.01 \\
Previous encephalopathy, $n$ & $18.8(13.5)$ & $12(7)$ & 0.02 \\
PPG reduction, mm Hg & $13.5(57 \%)$ & $3(5 \%)$ & 0.001 \\
Final PPG, mm Hg & $5.5(2)$ & $11(2)$ & 0.7 \\
& & $6(4.3)$ & 0.5 \\
\hline
\end{tabular}

Continuous variables are presented as medians (IQR), categorical variables as numbers (\%). PPG, portosystemic pressure gradient. See legend to Table 1 for further information.

sepsis $(n=3)$, acute hepatic failure $(n=2)$, and recurrence of variceal bleeding $(n=1)$.

Patients who died in the first month after TIPS placement had a significantly higher baseline Child-Pugh score ( $33 \%$ with score $\mathrm{C}$ vs. $6 \%$ with score $\mathrm{A}$ or $\mathrm{B} ; p=0.006$ ) and MELD score, and a significantly higher rate of prior history of encephalopathy (Table 3). The indication for TIPS placement (ascites vs. variceal bleeding) was not different between patients who died versus those who survived. OLT-free survival at 1 month and 1 year was 88.3 and $60 \%$, respectively. From the 15 patients who underwent liver transplantation, 3 (20\%) died after a median time of 0.8 (4.8) months. Patients who died after OLT had significantly higher baseline Child-Pugh and MELD scores (online suppl. Table 1; for all online suppl. material, see www.karger.com/doi/10.1159/000507894).

\section{Recurrent/Uncontrolled Bleeding}

Among the 18 patients in whom the indication for TIPS placement was refractory/recurrent variceal bleeding, a new episode of variceal bleeding was reported in 4 patients (22\%), in 3 of them within the first 30 days after the procedure. These patients had post-TIPS PPG median value of $8 \mathrm{~mm} \mathrm{Hg}$, but none $>12 \mathrm{~mm} \mathrm{Hg}$. Patients who experienced rebleeding had significantly lower baseline hemoglobin values (online suppl. Table 2). In 1 patient, outcome was fatal. Concerning the other 3 patients, 2 of them were submitted to elastic banding and 1 to Sengstaken-Blakemore tube placement. PPG was remeasured in 2 patients, both with $>12 \mathrm{~mm} \mathrm{Hg}$, submitted to TIPS dilation. 


\section{Ascites Response}

Among the 33 patients with refractory ascites and documented follow-up, a partial or complete response was confirmed in 11 (33.3\%) and 15 (45.5\%), respectively, and no response in 7 patients $(21.2 \%)$. These last patients had a median value of $7 \mathrm{~mm} \mathrm{Hg}$ after TIPS PPG; 1 patient had 14 $\mathrm{mm} \mathrm{Hg}$, with pre-TIPS PPG of $31 \mathrm{~mm} \mathrm{Hg}$. Significantly lower levels of baseline albumin were found in patients with failure of ascites control post-TIPS (online suppl. Table 3 ).

\section{Discussion}

Portal hypertension is an inevitable consequence of cirrhosis characterized by increased pressure gradient between the portal vein and the suprahepatic veins (hepatic venous pressure gradient $>5 \mathrm{~mm} \mathrm{Hg}$ ) [7]. Clinically significant portal hypertension, defined as hepatic venous pressure gradient $\geq 10 \mathrm{~mm} \mathrm{Hg}$, is responsible for many important complications of cirrhosis, with 2 of the most common being variceal bleeding and ascites [8]. The development of these complications marks the transition from a compensated to decompensated stage of cirrhosis, which is associated with a significant reduction in survival [9]. The TIPS procedure is used to decompress the portal venous system through its connection into the systemic circulation, therefore preventing rebleeding from varices and/or reducing ascites formation; it can also be used for other complications, such as hepatic hydrothorax or hepatorenal syndrome [10].

In patients with acute variceal bleeding, endoscopic treatment is initially preferred. However, it fails to control bleeding in $10-15 \%$ of cases [11]. In patients successfully treated with endoscopic band ligation, the risk of rebleeding can be reduced by the use of nonselective $\beta$-blockers to $45 \%$, by sequential endoscopic band ligation to $30 \%$, and by a combination of both to around 25\% [12]. Previous studies have demonstrated that in high-risk patients with Child-Pugh class $\mathrm{C}<14$ points or class $\mathrm{B}$ disease with active bleeding at presentation, the use of early TIPS (within $72 \mathrm{~h}$ after admission) was associated with improved bleeding control and mortality $[13,14]$. TIPS placement has also proven more effective in the prevention of rebleeding than any of the previous pharmacological or endoscopic therapies [12].

Refractory ascites, defined as fluid which cannot be mobilized despite sodium restriction and high-dose diuretics, or reaccumulates after therapeutic paracentesis, occurs in about $5-10 \%$ of patients with cirrhosis [15]. In these patients, TIPS placement has shown better control of ascites than medical treatment [15]. Indications for TIPS in our cirrhotic population were refractory ascites, variceal bleeding not controlled by endoscopic band ligation, or rebleeding of gastroesophageal varices, as in most cases [16]. In our study, technical success was $97.4 \%$, which is in agreement with other reports [17]. Hemodynamic success was achieved in all patients with technical success, as described elsewhere [18]. In patients with variceal bleeding, it is well established that if the PPG after TIPS creation can be reduced to $12 \mathrm{~mm} \mathrm{Hg}$ or less, the risk of bleeding will fall significantly [19]. Parvinian et al. [18] suggest a similar PPG threshold to control refractory ascites. In our population, even though 1 patient had a post-TIPS PPG $>12 \mathrm{~mm} \mathrm{Hg}$, TIPS was effective in reducing PPG values $>20 \%$ from baseline in all patients.

First-month mortality is related to the clinical characteristics of patients, ranging from 3 to $44 \%$ [20]. In our study, 30 -day mortality was $11.7 \%$, which is similar to that reported by Pan et al. [21]. Patients who died after TIPS placement had a significantly higher rate of previous HE and higher baseline Child-Pugh and MELD scores. Survival is associated with liver functional reserve [22]. MELD score was initially created to predict the 3-month mortality in patients undergoing elective TIPS placement [23]. As liver failure and portal hypertension deteriorate, serum bilirubin, INR, and creatinine levels rise, therefore increasing MELD levels. Previous studies have indicated that MELD is useful in identifying patients at higher risk of early death $[24,25]$. Regardless of TIPS indication, patients with higher Child-Pugh score tend to have poor survival [26]. Pre-TIPS HE has already been described as an independent risk factor for mortality after TIPS [20]. OLT-free survival ranges from 48 to $90 \%$ in patients undergoing TIPS for variceal bleeding and from 48 to $91 \%$ when used for refractory ascites [5]. In our population, OLT-free survival at 1 month and 1 year was 88.3 and $60 \%$, respectively. Patients who died after OLT presented significantly higher baseline Child-Pugh and MELD scores, which are both associated with more advanced disease.

The success rate of TIPS for controlling recurrent bleeding was satisfactory in our population, as only $22 \%$ experienced rebleeding. A recent meta-analysis analyzing 24 studies from 12 different countries obtained similar results [27], confirming its superiority to endoscopic treatment for this purpose. A pre-TIPS lower hemoglobin value was significantly associated with rebleeding after TIPS, as also reported by Kim et al. [28]. Variceal embolization performed as an adjunctive therapy during TIPS procedure has the potential to help preventing recurrent bleeding by occluding venous collateral channels [29]. 
Development of ascites is a poor prognostic factor in patients with cirrhosis, with a 1- and 2-year mortality of about 40 and 50\%, respectively, and a median survival of 6 months once it becomes refractory to treatment [9]. In our population, TIPS placement was effective for refractory ascites, with response in $78.8 \%(n=26)$ of patients $(33.3 \%$ achieving partial and $45.5 \%$ complete response), as seen in other reports $[22,30]$. In our study, patients in whom ascites control failed were found to have significantly lower levels of baseline albumin, which is in line with the role of albumin in the pathophysiology of ascites [31].

The main complication of TIPS insertion is the development or worsening of $\mathrm{HE}$, ranging from 25 to $45 \%$ [32]. Metabolites present in the portal circulation requiring hepatic detoxification bypass the liver through TIPS and enter directly into the systemic circulation, contributing to post-TIPS HE [32]. Despite its relatively high rate, most patients with post-TIPS HE respond well to conservative treatment with dietary modification and medical therapy [33]. Only $3-7 \%$ of patients develop recurrent or refractory HE, which may need reduction or occlusion of the shunt as conservative treatment alone is not sufficient [17]. In our series, $41 \%(n=21)$ of patients developed HE; older age and higher levels of creatinine were significantly higher in those patients. Impaired renal function has been found to predict post-TIPS HE occurrence [34]. As liver disease deteriorates, it causes hemodynamic changes which decrease renal function. Patients will also be more susceptible to HE; possible explanations include a decrease in first-pass hepatic clearance of ammonia and an increase in splanchnic blood flow, which increases the amount of circulating ammonia [35]. A meta-analysis including 30 studies with a total of 3,006 patients identified increased age as a robust predictor of post-TIPS HE [36]. The development of HE is also associated with shunt diameter [37]. A possibility to reduce post-TIPS HE incidence is the use of stents with a smaller diameter, therefore reducing the amount of blood shunted into the systemic circulation [38]; however, it may be associated with less efficient control of portal hypertension [39]. The mean values of the final PPG compared between patients experiencing adverse events (namely HE), mortality, bleeding, or ascites control was not significantly different. These features highlight the fact that after a technically successful TIPS procedure, all outcomes depend on patient selection and probably timing of the procedure and not on the procedure itself. All technically successful TIPS procedures allowed for a hemodynamic success. The timing of the TIPS procedure also plays a crucial role (even though not evaluated in this study), as referral should not be delayed to the terminal stage of cirrhosis; late interventions are associated with higher morbidity and mortality rates and lower clinical success.

The present study is limited by its retrospective nature, with a relatively small and heterogeneous sample size with potential selection bias due to the number of patients lost to follow-up and the absence of a control group. Previous studies have demonstrated that deep sedation adds variability to pressure values and recommend PPG measurements after the patient had fully recovered from sedation $[40,41]$. Such changes can be attributed either to direct hemodynamic effects of sedative drugs used or to difficulty in accurate measurements of pressure values due to changes in the respiratory pattern. In our study, all patients received general anesthesia with liver hemodynamic values measured exactly under the same conditions before and after the procedure. Changes in PPG reflect the impact of TIPS placement, even though these changes from baseline may be affected by general anesthesia, which could have under- or overestimated the magnitude of the treatment effect. Regarding statistical analysis, we did not use logistic regression models as the results of data analysis would be limited by our small sample size, potentially leading to inadequate conclusions. Another limitation is that follow-up was not standardized; being a referral center, many patients that received TIPS returned to their original institution after the procedure, making proper long-term surveillance difficult. Despite these limitations, the present study could provide valuable information as it represents real-life experience, and we believe that these findings may serve as a basis for further investigations and improvements in clinical practice.

In conclusion, the TIPS procedure is a valid and safe option for managing patients with portal hypertensionrelated complications refractory to standard treatments, mainly ascites and variceal bleeding. However, being a procedure with potential complications, careful patient selection is essential to improve long-term outcomes.

\section{Statement of Ethics}

Given the observational character of the study, the local ethics committee waived the need for individual informed consent. The principles of the Declaration of Helsinki were respected throughout the study.

\section{Disclosure Statement}

The authors have no conflicts of interest to declare.
Santos et al. 
1 Strunk H, Marinova M. Transjugular Intrahepatic Portosystemic Shunt (TIPS): Pathophysiologic Basics, Actual Indications and Results with Review of the Literature. RoFo. 2018 Aug;190(8):701-11.

2 Rössle M. TIPS: 25 years later. J Hepatol. 2013 Nov;59(5):1081-93.

3 Krajina A, Hůlek P, Fejfar T, Valek V. Quality improvement guidelines for Transjugular Intrahepatic Portosystemic Shunt (TIPS). Cardiovasc Intervent Radiol. 2012 Dec;35(6): 1295-300.

4 Burgos AC, Thornburg B. Transjugular Intrahepatic Portosystemic Shunt Placement for Refractory Ascites: Review and Update of the Literature. Semin Intervent Radiol. 2018 Aug; 35(3):165-8.

5 Dissegna D, Sponza M, Falleti E, Fabris C, Vit A, Angeli P, et al. Morbidity and mortality after transjugular intrahepatic portosystemic shunt placement in patients with cirrhosis. Eur J Gastroenterol Hepatol. 2019 May;31(5): 626-32.

6 World Medical Association. World Medical Association Declaration of Helsinki: ethical principles for medical research involving human subjects. JAMA. 2013 Nov;310(20): 2191-4.

7 Kumar A, Sharma P, Sarin SK. Hepatic venous pressure gradient measurement: time to learn! Indian J Gastroenterol. 2008 Mar-Apr; 27(2):74-80.

8 Garcia-Tsao G, Abraldes JG, Berzigotti A, Bosch J. Portal hypertensive bleeding in cirrhosis: Risk stratification, diagnosis, and management: 2016 practice guidance by the American Association for the study of liver diseases. Hepatology. 2017 Jan;65(1):310-35.

9 Angeli P, Bernardi M, Villanueva C, Francoz C, Mookerjee RP, Trebicka J, et al. EASL Clinical Practice Guidelines for the management of patients with decompensated cirrhosis. J Hepatol. 2018;69(2):406-60.

10 Tripathi D, Stanley AJ, Hayes PC, Travis S, Armstrong MJ, Tsochatzis EA, et al. Transjugular intrahepatic portosystemic stentshunt in the management of portal hypertension. Gut. 2020 Feb;29:gutjnl-2019-320221.

11 Gupta A, Mehta AP, Mishra N, Bansal RK, Yadav AC. Effectiveness of Transjugular Intrahepatic Portosystemic Shunt in Variceal Bleeding: An Audit from a Tertiary Care Center in North India. J Clin Interv Radiol. 2017. Available from: https://doi.org/10.1055/ s-0037-1603888.

12 Sauerbruch T, Wong F. Treatment of Oesophageal Varices in Liver Cirrhosis. Digestion. 2019;99(4):261-6.

13 García-Pagán JC, Caca K, Bureau C, Laleman W, Appenrodt B, Luca A, et al.; Early TIPS (Transjugular Intrahepatic Portosystemic Shunt) Cooperative Study Group. Early use of TIPS in patients with cirrhosis and variceal bleeding. N Engl J Med. 2010 Jun;362(25): 2370-9.
14 Hernández-Gea V, Procopet B, Giráldez Á, Amitrano L, Villanueva C, Thabut D, et al.; International Variceal Bleeding Observational Study Group and Baveno Cooperation. Preemptive-TIPS improves outcome in high-risk variceal bleeding: an observational study. Hepatology. 2019 Jan;69(1):282-93.

15 Nusrat S, Khan MS, Fazili J, Madhoun MF. Cirrhosis and its complications: evidence based treatment. World J Gastroenterol. 2014 May;20(18):5442-60.

16 Fagiuoli S, Bruno R, Debernardi Venon W, Schepis F, Vizzutti F, Toniutto P, et al.; AISF TIPS Special Conference. Consensus conference on TIPS management: Techniques, indications, contraindications. Dig Liver Dis. 2017 Feb;49(2):121-37.

17 Herzer K, Lindner D, Nolte-Ernsting C, Gerken G, Hilgard P. Patient Selection, Outcome and Clinical Efficacy of TIPS: A Single Center Experience and Review of the Literature. J Gastroenterol Hepatol Res. 2015 Jan; 4(4):1557-64.

18 Parvinian A, Bui JT, Knuttinen MG, Minocha J, Gaba RC. Transjugular intrahepatic portosystemic shunt for the treatment of medically refractory ascites. Diagn Interv Radiol. 2014 Jan-Feb;20(1):58-64.

19 Boyer TD, Haskal ZJ; American Association for the Study of Liver Diseases. The role of transjugular intrahepatic portosystemic shunt (TIPS) in the management of portal hypertension: Update 2009. Hepatology. 2010 Jan;51(1):306-306.

20 Chalasani N, Clark WS, Martin LG, Kamean J, Khan MA, Patel NH, et al. Determinants of mortality in patients with advanced cirrhosis after transjugular intrahepatic portosystemic shunting. Gastroenterology. 2000 Jan;118(1): $138-44$.

21 Pan JJ, Chen C, Caridi JG, Geller B, Firpi R, Machicao VI, et al. Factors predicting survival after transjugular intrahepatic portosystemic shunt creation: 15 years' experience from a single tertiary medical center. J Vasc Interv Radiol. 2008 Nov;19(11):1576-81.

22 Qin JP, Jiang MD, Tang W, Wu XL, Yao X, Zeng WZ, et al. Clinical effects and complications of TIPS for portal hypertension due to cirrhosis: a single center. World J Gastroenterol. 2013 Nov;19(44):8085-92.

23 Malinchoc M, Kamath PS, Gordon FD, Peine CJ, Rank J, ter Borg PC. A model to predict poor survival in patients undergoing transjugular intrahepatic portosystemic shunts. Hepatology. 2000 Apr;31(4):864-71.

24 Gotlieb N, Brill J, Shibolet I, Sherf-Dagan S, Kori I. Characteristics, Outcomes and Predictors of Mortality in Patients Undergoing Transjugular Intrahepatic Portosystemic Shunt. J Clin Gastroenterol Hepatol. 2018; 2(3): 15 .

25 Montgomery A, Ferral H, Vasan R, Postoak DW. MELD score as a predictor of early death in patients undergoing elective transjugular intrahepatic portosystemic shunt (TIPS) procedures. Cardiovasc Intervent Radiol. 2005 May-Jun;28(3):307-12.

26 Membreno F, Baez AL, Pandula R, Walser E, Lau DT. Differences in long-term survival after transjugular intrahepatic portosystemic shunt for refractory ascites and variceal bleed. J Gastroenterol Hepatol. 2005 Mar;20(3): 474-81.

27 Zhang $\mathrm{H}$, Zhang $\mathrm{H}$, Li H, Zhang H, Zheng $\mathrm{D}$, Sun CM, et al. TIPS versus endoscopic therapy for variceal rebleeding in cirrhosis: A meta-analysis update. J Huazhong Univ Sci Technolog Med Sci. 2017 Aug;37(4): 475-85.

28 Kim HK, Kim YJ, Chung WJ, Kim SS, Shim JJ, Choi MS, et al. Clinical outcomes of transjugular intrahepatic portosystemic shunt for portal hypertension: korean multicenter realpractice data. Clin Mol Hepatol. 2014 Mar; 20(1):18-27.

29 Gaba RC, Omene BO, Podczerwinski ES, Knuttinen MG, Cotler SJ, Kallwitz ER, et al. TIPS for treatment of variceal hemorrhage: clinical outcomes in 128 patients at a single institution over a 12 -year period. J Vasc Interv Radiol. 2012 Feb;23(2):227-35.

30 Piecha F, Radunski UK, Ozga A-K, Steins D, Drolz A, Horvatits T, et al. Ascites control by TIPS is more successful in patients with a lower paracentesis frequency and associated with improved survival. JHEP Rep. 2019 May;1(2): 90-98.

31 Walayat S, Martin D, Patel J, et al. Role of albumin in cirrhosis: from a hospitalist's perspective. J Community Hosp Intern Med Perspect. 2017 Mar;7(1):8-14.

32 Riggio O, Nardelli S, Moscucci F, Pasquale C, Ridola L, Merli M. Hepatic encephalopathy after transjugular intrahepatic portosystemic shunt. Clin Liver Dis. 2012 Feb;16(1):133-46.

33 Madoff DC, Wallace MJ. Reduced stents and stent-grafts for the management of hepatic encephalopathy after transjugular intrahepatic portosystemic shunt creation. Semin Intervent Radiol. 2005 Dec;22(4):316-28.

34 Riggio O, Angeloni S, Salvatori FM, De Santis A, Cerini F, Farcomeni A, et al. Incidence, natural history, and risk factors of hepatic encephalopathy after transjugular intrahepatic portosystemic shunt with polytetrafluoroethylene-covered stent grafts. Am J Gastroenterol. 2008 Nov; 103(11): 2738-46.

35 Madoff DC, Wallace MJ, Ahrar K, Saxon RR. TIPS-related hepatic encephalopathy: management options with novel endovascular techniques. Radiographics. 2004 Jan-Feb; 24(1):21-36.

36 Bai M, Qi X, Yang Z, Yin Z, Nie Y, Yuan S, et al. Predictors of hepatic encephalopathy after transjugular intrahepatic portosystemic shunt in cirrhotic patients: a systematic review. J Gastroenterol Hepatol. 2011 Jun; 26(6):943-51. 
37 Qi XS, Bai M, Yang ZP, Fan DM. Selection of a TIPS stent for management of portal hypertension in liver cirrhosis: an evidence-based review. World J Gastroenterol. 2014 Jun; 20(21):6470-80.

38 Schepis F, Vizzutti F, Garcia-Tsao G, Marzocchi G, Rega L, De Maria N, et al. Underdilated TIPS associate with efficacy and reduced encephalopathy in a prospective, nonrandomized study of patients with cirrhosis. Clin Gastroenterol Hepatol. 2018 Jul;16(7): 1153-1162.e7.
39 Riggio O, Ridola L, Angeloni S, Cerini F, Pasquale C, Attili AF, et al. Clinical efficacy of transjugular intrahepatic portosystemic shunt created with covered stents with different diameters: results of a randomized controlled trial. J Hepatol. 2010 Aug;53(2):267-72.

40 Reverter E, Blasi A, Abraldes JG, MartínezPalli G, Seijo S, Turon F, et al. Impact of deep sedation on the accuracy of hepatic and portal venous pressure measurements in patients with cirrhosis. Liver Int. 2014 Jan;34(1):1625.
41 Silva-Junior G, Turon F, Baiges A, Cerda E, García-Criado Á, Blasi A, et al. Timing affects measurement of portal pressure gradient after placement of transjugular intrahepatic portosystemic shunts in patients with portal hypertension. Gastroenterology. 2017 May;152(6): 1358-65. 